\title{
Preventive Effects of Ellagic Acid on Nucleus Tractus Solitarius Electrical Activity and Oxidative Stress Altered by Cerebral Global Ischemia/Reperfusion in Rat
}

\author{
Khojasteh Hoseiny Nejad ${ }^{1}$, Alireza Sarkaki ${ }^{2}$, Mahin Dianat ${ }^{2}$, Yaghoob Farbood ${ }^{1}$, \\ Mohammad Badavi ${ }^{2}$,Mohammad Kazem Gharib-Naseri ${ }^{2}$. \\ ${ }^{1}$ Abadan Arvand International Division, Ahvaz Jundishapur University of Medical Sciences, Ahvaz, Iran; \\ ${ }^{2}$ Physiology Research Center and Department of Physiology, Ahvaz Jundishapur University of Medical Science, \\ Ahvaz, Iran.
}

\begin{abstract}
Cerebral ischemia commonly occurs when the blood flow to the entire brain or some part of the brain is disrupted. Global cerebral ischemia attenuates the nucleus tractus solitaries (NTS) EEG rhythm, increases the free radicals production and brain inflammation. Ellagic acid (EA) has antioxidative and anti-inflammatory effects against neural damages. The aim of this study was to evaluate the role of ellagic acid on EEG power in the global cerebral ischemia.Rats were divided into four groups: SO (sham) received normal saline, EA+SO, I/R (normal saline + ischemia/reperfusion), and EA + I/R. EA (100 mg/kg, dissolved in normal saline) or normal saline was administered orally (gavage) for 10 days. Animal underwent to 20 minutes of ischemia followed by 30 minutes of reperfusion in $I / R$ and I/R+EA groups. EEG was recorded from NTS and serum antioxidant enzyme activity was measured.Data showed that ellagic acid improved electrical power of NTS. Theta and delta bands frequencies in the ischemic animals were decreased in I/R group with compared to SO group significantly $(P<0.001)$. Ellagic acid has beneficial effect on superoxide dismutase activity in the ischemic animals with compared to I/R group $(P<0.01)$. In contrast, ellagic acid has no significant role on glutathione peroxidase activity in the pretreated ischemic rats in comparison with I/R group.These findings suggest that ellagic acid increased antioxidant enzymes activity that scavenge the ROS due to ischemia so that it may have neuroprotective effect on NTS neurons and consequently reverse its electrophysiology pattern.
\end{abstract}

Key words: Ellagic acid; EEG; Antioxidant; Cerebral ischemia/reperfusion; Rat

\footnotetext{
*Author for correspondence: dianat@ajums.ac.ir
} 


\section{INTRODUCTION}

Cerebral ischemia commonly happens when the blood flow to the entire brain or some part of the brain is disrupted which ensuing in the brain tissue deficiency of oxygen and glucose and may injure neuronal cells forever [1]. Focal ischemia also called brain stroke and global ischemia occurs in some situations such as cardiac arrest, coronary artery bypass surgery and cardiorespiratory failure [2,3]. In addition, cerebral ischemia is second cause of death in the universe, so many investigators focused on severe cerebral ischemia (global cerebral ischemia) to minimize the lesion and neurodegeneration [4].

In the electroencephalography (EEG) recording, the cortical electrical activity has been categorized affording to the frequency/spectral content of the signals [5]. With a growing body of evidences, EEG rhythms become slow during global cerebral ischemia [6,7]. It has been established that the EEG signal records denotes numerous phases of brain recovery and signals flattening rapidly if cerebral blood flow reduced drastically such as in the global cerebral ischemia situation $[8,9]$. Each pattern of EEG sub-waves namely delta, theta, alpha, beta, and gamma waves has described development of during global cerebral ischemia and after reperfusion [10,11,12]. Several line of investigations revealed that theta and delta bands are more susceptible to cerebral ischemia $[13,14]$.

The preventive role of phytochemicals and phenolic compounds were found against cerebral ischemia [15]. Ellagic acid is a secondary metabolite of many natural plants, particularly fruits such as strawberry, cranberry, and raspberry [16]. Phenolic profiles and antioxidant capacities of the ellagic acid have been proved in many neurodegenerative diseases $[17,18]$. Also, ellagic acid ameliorated the cell death and apoptosis during focal cerebral ischemia [19] but there is no evidence over the role of ellagic acid in experimental model of cardiac arrest or global cerebral ischemia.

NTS was attends to incorporate cardio-respiratory reflexes and also encourage behaviors activities and adjust the cerebral cortex of brain electrical activity [20, 21]. Therefore, stimulation of the NTS electrically may alter brain electrophysiology activity and ameliorates the EEG frequency [22, 23]. As well as modulatory role on electrical activity, the NTS stimulation regulates cerebral blood flow [24]. Accordingly, monitoring NTS electrical activity via local EEG recording is helpful method to monitor global cerebral ischemia.

Previous findings indicated that ellagic acid has amended brain electrophysiological activity in neuronal damages such as traumatic brain injury and Parkinson's disease [18]. In continue of these investigations, we planned to record the local EEG pattern of nucleus tractus solitaries (NTS) in rats after global cerebral ischemia/reperfusion (I/R) that pretreated with ellagic acid. In this study, EEG frequency powers of NTS such as theta and delta bands in $\mathrm{I} / \mathrm{R}$ rats were measured. To identifying the antioxidant properties of ellagic acid, we measured glutathione peroxidase and superoxide dismutase activity and also cytokines in the blood serum samples.

\section{MATERIAL AND METHODS}

Thirty two adult male Wister rats (280-300 g) were obtained from Laboratory Animals Breading Center of Ahvaz Jundishapur University of Medical Sciences and housed in standard cages under controlled temperature $(22 \pm 2 \mathrm{oC})$, humidity and a 12 h light/dark cycle (light on 07:00 am), with food and water ad libitum. All animals were handled before testing for 5 days (10 minutes daily) [25]. The experiments were approved by Local Committee of Animal Ethics in Ahvaz Jundishapur University of Medical Sciences (No.ajums.B-9348). All efforts were done to minimize animal suffering, and to reduce the number of animals used. 
Rats were divided randomly into four groups of eight rats in each, as following: 1) $\mathrm{SO}$ (sham operated); were only received $1.5 \mathrm{ml} / \mathrm{kg}$ solvent orally by gavage for 10 consecutive days before tests, 2) EA+SO; received $100 \mathrm{mg} / \mathrm{kg}$ EA orally by gavage for 10 consecutive days before tests, 3) I/R; rats received $1.5 \mathrm{~mL} / \mathrm{kg}$ of solvent by gavage for 10 consecutive days and then were exposed to global cerebral ischemia for $20 \mathrm{~min}$ and subsequently $30 \mathrm{~min}$ reperfusion (I/R), and 4) EA+I/R; rats received ellagic acid $(100 \mathrm{mg} / \mathrm{kg} /$ day $)$ orally by gavage for 10 consecutive days before $\mathrm{I} / \mathrm{R}[26]$. The dose of EA $(100 \mathrm{mg} / \mathrm{kg})$ was selected based on previous reports and our pilot experiments $[7,18,27]$. Induction of $\mathrm{I} / \mathrm{R}$ was carried out 24 hours after last gavage.

\section{Chemicals and compounds}

Ketamine hydrochloride and xylazine (Alfasan Co., Holland), ellagic acid and dimethyl sulfoxide (DMSO) p u r c h a s e d f r om Sigma-Aldrich Co. (USA). Ellagic acid was dissolved in DMSO/normal saline (10\%), buffered to a $\mathrm{pH}=7,(100$ $\mathrm{mg} / \mathrm{kg} / 1.5 \mathrm{ml}$, daily by gavages for 10 days).

\section{Surgery}

Rats were anaesthetized with ketamine/xylazine $(100 / 5 \mathrm{mg} / \mathrm{kg} \mathrm{w} / \mathrm{w})$, body temperatures were monitored using heating pads and their heads mounted in a stereotaxic device for electrode implantation surgery before I/R surgery. A teflon coated stainless steel bipolar metal wire electrode (0.005" bare, 0.008" coated, A-M systems, Inc. WA) was implanted into the brain NTS with stereotaxic coordination according to rat brain stereotaxic atlas of Paxinos' and Watsons' [28]: AP:-14.04 $\mathrm{mm}$ to bregma; ML:0.4 mm, and DV:8 mm from the dura respectively. All implants were fixed to the skull by dental acrylic cement and two stainless steel glass anchor small screws [29, 30]. Establishment of microelectrodes at the right site was confirmed by passing the DC through the active wire in order to making lesion at electrode tip point and histological section performed at the end of experiments.

\section{Local EEG recording}

Electrical field potentials (local EEG) from the NTS of anaesthetized rats were fed to an ML135bio-amplifier, 4-Channels PowerLab and LabChart Software version 7. (ADInstruments, Australia) with $1 \mathrm{mV}$ amplification, sample recording $400 \mathrm{~Hz}$, and $0.3-70 \mathrm{~Hz}$ band pass filtration for 5 minute. The basic EEG variations period of 5 seconds were compared in all groups before and after I/R induction in the related groups. Electrical power of frequency bands were measured as $\mu \mathrm{V} 2 / \mathrm{Hz}$ [30]. The local EEG recording was done at 1 st and 11 th days before and after I/R.

\section{Induction of global cerebral $\mathbf{I} / \mathbf{R}$}

On the first day, after anesthesia, animals underwent transient forebrain global ischemia, as described by Pulsinelli and Brierley [31]. As briefly, a neck ventral mid line incision was made, the common carotid arteries (CCA) were exposed and separated from the vagus nerves. Then, a sterile field around each common carotid artery was carefully placed, without interrupting the carotid blood flow and the incision was then sutured. A second incision, $1 \mathrm{~cm}$ in length, covering direct occipital bone at the back of the first two cervical vertebrae was then made. The muscles around the spine from the midline, separating the left and right alar hole of the first cervical vertebrae were thus exposed. Vertebral artery spinal canal passed under the alar foramen before the posterior fossa. $0.5 \mathrm{~mm}$ diameter electrocautery needles (Bowie Monopolar Electrocautery, Cincinnati, Ohio) were placed through each vertebral artery foramen

electrocauterized alar, and were permanently blocked. 
On the second day, under anesthesia, both CCA were occluded by microclamps for 20 minutes to produce 4-vessel occlusion (4VO) [26]. Reperfusion (30 minute duration) was started by opening the carotid clamps after 20 minutes of ischemia. Only ischemic rats with flattened EEG during the ischemia period were assigned to further studies [32]. Similar procedures were carried out in SO and EA+ SO groups without vertebral arteries electro-coagulation and carotid arteries occlusion [33]. The blood samples were collected from the heart and after coagulation (at room temperature) was centrifuged at $4000 \mathrm{rpm}$ (10 minutes at ambient temperature). The collected serum samples were stored at $-80{ }^{\circ} \mathrm{C}$ until assay.

\section{Measurement of the serum antioxidants enzymes}

Superoxide dismutase of the collected serum samples was measured spectrophotometrically using appropriate kits (Pars Azmoon Co., Iran) and its level was calculated according the kit's instruction. The absorbance was read at $450 \mathrm{~nm}$ according to manufacturer's instructions. The final presentation of SOD activity was unit per milligram of protein. [34].

Glutathione peroxidase of the collected serum samples was detected using appropriate kits (Pars Azmoon Co., Iran) and its level was calculated according the kit's instrument. GPx activity was determined in serum samples by spectrophotometry at $340 \mathrm{~nm}$ using a commercially available kit (Pars Azmoon Co., Iran) The GPx activity was unit per milligram of protein. [35].

\section{Statistical analysis}

All data were presented as mean \pm SEM and were assessed by one- way ANOVA followed by Tukey's post hoctest. The $P$-values less than 0.05 were assigned as significance difference.

\section{RESULTS}

\section{Timeline of EEG records before and after global cerebral ischemia}

Figure 1 represents the timeline of EEG records before ischemia induction (base line EEG), during ischemia and reperfusion phases. During ischemia the EEG power fall down compared to base line. During reperfusion EEG pattern started to increase its power.

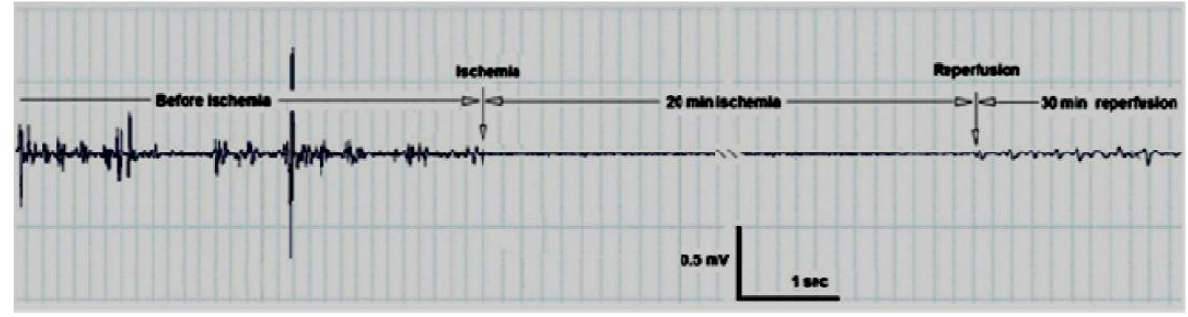

Figure 1 -

\section{EEG power of experimental groups}

Recorded local EEG from NTS before beginning the gavage at the first day of experiment showed that in all groups the EEG power were identical and normal (fig.2A). Pretreatment with ellagic acid or normal saline for 10 days also had no significant effect on EEG power before I/R induction (fig. 2B).

Results of EEG power showed that there was no difference between before ischemia and reperfusion phases in $\mathrm{SO}, \mathrm{EA}+\mathrm{SO}$, and also $\mathrm{EA}+\mathrm{IR}$ groups while it decreased significantly in $\mathrm{I} / \mathrm{R}$ group after $\mathrm{I} / \mathrm{R}$ induction $(P<0.01)$. On the other hand, 10 days ellagic acid pretreatment in ischemic animals reversed the power of EEG significantly with compare to IR $(P<0.01$, Fig. 3$)$. 
Ellagic acid protects brain from I/R
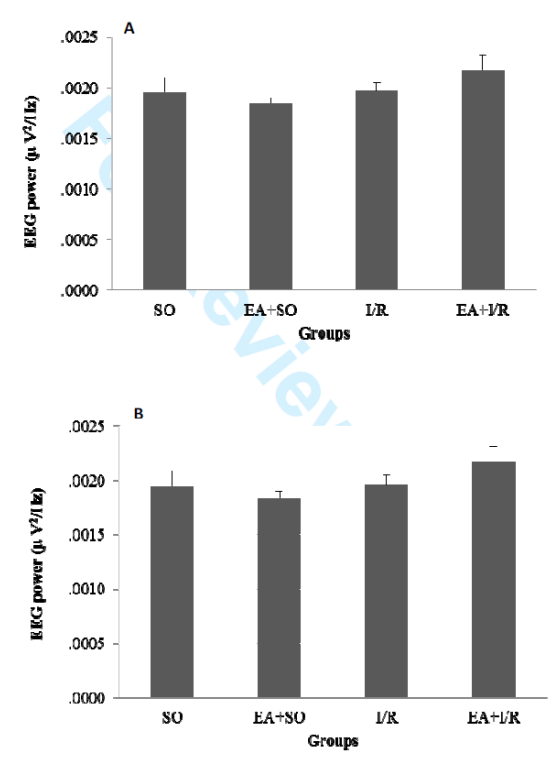

Figure 2 -

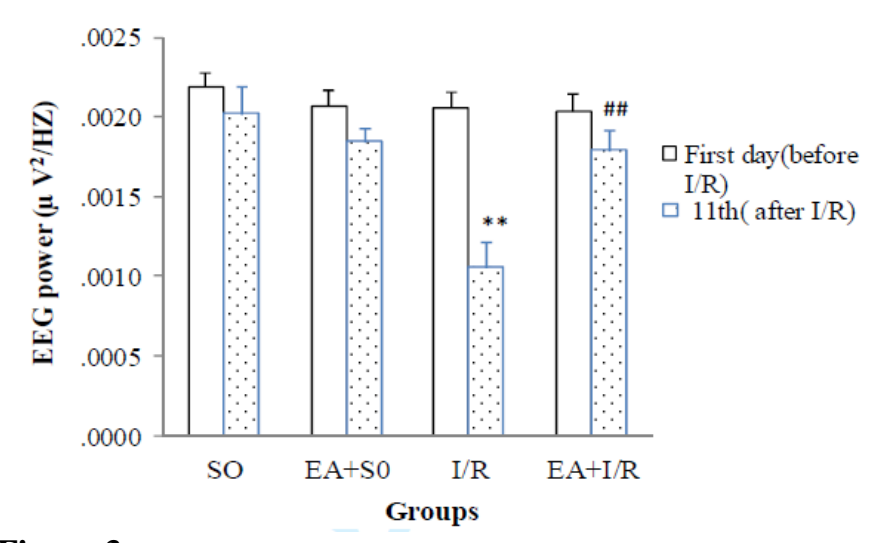

Figure 3 -

Theta band power was detected in the reperfusion phase, as shown in figure 4 , data showed that theta band power had no significant change between SO and EA+SO groups while decreased significantly in $\mathrm{I} / \mathrm{R}$ when compared with $\mathrm{SO}$ group $(P<0.001)$. Theta power increased in pretreated $\mathrm{EA}+\mathrm{I} / \mathrm{R}$ group with $\mathrm{EA}$ in comparison to I/R group significantly $(P<0.001$, Fig. $4 \mathrm{~A})$.

Delta band power was also detected in the reperfusion phase, as shown in figure 4 , delta band power had no significant change between SO and EA+SO groups while decreased significantly in $\mathrm{I} / \mathrm{R}$ when compared with $\mathrm{SO}$ group $(P<0.001)$. Delta power increased in pretreated $\mathrm{EA}+\mathrm{I} / \mathrm{R}$ group with $\mathrm{EA}$ in comparison to $\mathrm{I} / \mathrm{R}$ group significantly $(P<0.001$, Fig. 4B). 

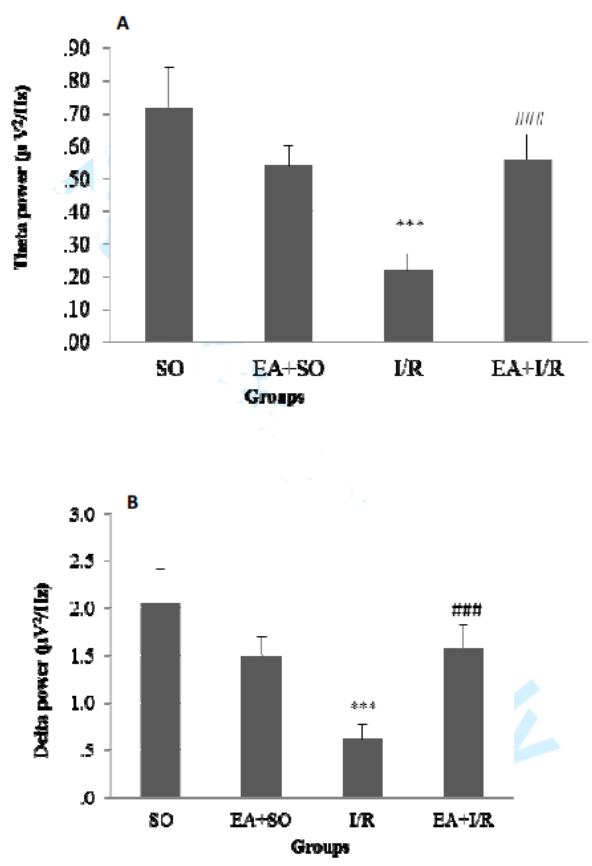

Figure 4 -

\section{Serum antioxidants levels}

As figure 5 shows SOD and GPx levels in serum, SOD had no significant change between $\mathrm{SO}$ and $\mathrm{EA}+\mathrm{SO}$ groups while decreased significantly in $\mathrm{I} / \mathrm{R}$ when compared with SO group $(P<0.001)$. SOD increased in pretreated $\mathrm{EA}+\mathrm{I} / \mathrm{R}$ group with comparison to I/R group significantly $(P<0.01$, Fig. $5 \mathrm{~A})$, although it was lesser than in SO group. Serum GPx level was reduced in the $\mathrm{I} / \mathrm{R}$ with compared to $\mathrm{SO}$ group $(P<0.01$, Fig. 5B). Pretreatment of I/R rats with ellagic acid couldn't change itslevel.
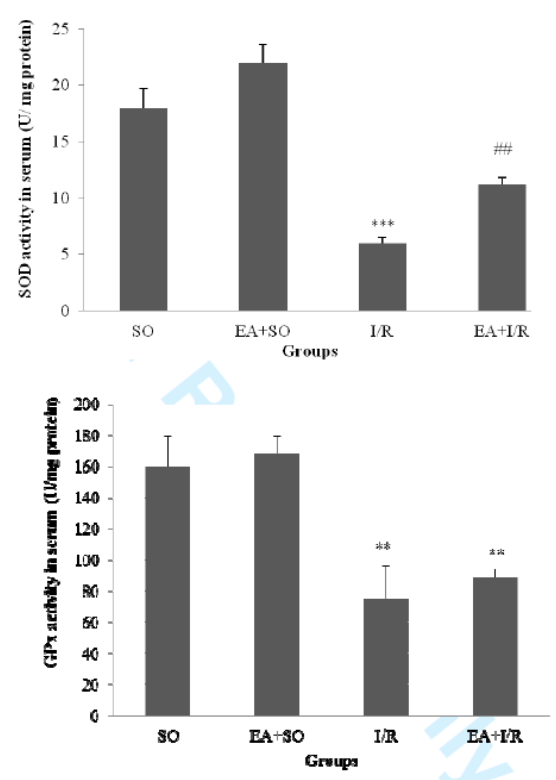

FIGURE 5 - 
Ellagic acid protects brain from I/R

\section{DISCUSSION}

In the present study, we monitored and analyzed the protective effects of ellagic acid on brain NTS local EEG and its two sub-frequency powers (theta and delta) following transient global $(4-\mathrm{VO})$ cerebral $\mathrm{I} / \mathrm{R}$. Current results recognized that ellagic acid significantly protected the I/R disruptive against EEG power. To illustrating more details about role of ellagic acid against global cerebral ischemia, we detected EEG and also its two sub-frequencies powers (theta and delta). Besides it, serum antioxidant enzymes levels such as SOD and GPx were evaluated. SOD level was increased in treated ischemic animals with ellagic acid while, had no defensive role on serum GPx level in same animals.

Antioxidant role of polyphenols was discovered from ancient times and these compounds were used in traditional medicine. Ellagic acid was a derivation of ellagitannins which taken from some fruits and plants [36,37]. The main subject related to neurodegenerative diseases was oxidative toxicity and the neuroprotective role of ellagic acid as polyphenol was predictable.

However, several lines of studies demonstrated that ellagic acid could influence antioxidant enzymes and hence defenses brain from any neuronal oxidative conditions such as Alzheimer's disease, brain trauma, Parkinson's disease and focal cerebral ischemia $[18,19,38,39]$. The precise role of ellagic acid against global cerebral ischemia which is an experimental model of cardiac arrest has not been distinguished. Based on our previous studies, the dose of $100 \mathrm{mg} / \mathrm{kg}$ EA has more protective role against neuronal and myocardial injury [40], thus we used same dose of EA on EEG power and antioxidant enzymes in I/R animals. Since, NTS of brain is an important area regulates baro-reflexes and other cardiorespiratory function in both normal and pathophysiological states [41, 42], we targeted NTS region to detect EEG power and ECG changes in experimented subjects simultaneously.

Al-Nashash and Thakor in 2005 checked the five sub-frequencies powers of EEG records after global cerebral ischemia which induced by asphyxic cardiac arrest [43]. They demonstrated that all sub-frequencies powers were changed during and after global cerebral ischemia and these alterations of each sub-frequency power was dependent on time of records in reperfusion phase from rodent brain [43]. Similarly, Bezerianos and colleagues confirmed that there is a relationship between time point of record following reperfusion and EEG sub-frequencies powers [44]. However, many researches detected the global cerebral ischemia role on EEG power [45, 46] but our findings established the all sub-frequencies powers changed in the $4-\mathrm{VO}$ model after 30 minutes reperfusion peroid. Although, time-dependent study should be performed in the future studies and analyzed the EEG sub-frequencies powers with respect to time course in the reperfusion phase for illuminating more knowledge in sub-wavelets adjustments. Ellagic acid, as a potent phenol, improved NTS local EEG power and its bands frequencies. Our observations are in agreement with our newly published data and also with Pang et al., 2014 findings for

beneficial role of ellagic acid against global and focal cerebral ischemia respectively $[19,40]$.

However, the long-time study in reperfusion phase to show more specific role and perceive mechanism of EA effect should be designed in future studies.

Several line of evidences consistently supports the claim that ellagic acid improves antioxidant enzymes and subsequently these enzymes might defend neuronal cells against produced free radicals in brain injuries $[47,48,49]$. Herein, we detected the two antioxidant enzymes (SOD and GPx) in the present or absence of ellagic acid in ischemic rats' tissues. Ellagic acid could recover SOD level in the ischemic animals and conversely, GPx level was not changed by administration of EA in ischemic rats. 
With respect to numerous reports in antioxidant role of EA on neuodegeneration [4750], we can confirm anti-oxidative profile of EA. The SOD enzyme produces substrate for GPx activity in the brain under stressful situations [51, 52]. Consistent with very short time of reperfusion in the current study (30 minutes reperfusion), we might proposed that brain level of GPx was not reached into high level in this time point so we can suggest that long time reperfusion following a cerebral ischemia required. Moreover, EA has no role in the SOD and GPx levels alone which revealed the EA antioxidative role probably faced under

harmful condition. Our reports and also other studies confirmed this observation that EA triggered antioxidant enzymes following injuries [7, 18, 40, 50].

Some studies have been shown that deficits or inhibition of antioxidant enzymes has a key influence on NMDA and GABA receptors in the brain $[41,53]$; these receptors modulate synaptic plasticity and down-regulation of these receptors caused behavioral and electrophysiological abnormities $[54,55]$. As a result, perhaps EA has defensive effect on EEG pattern through activation of antioxidant enzymes.

\section{CONCLUSION}

In conclusion, it is recommended that EA pretreatment could enhance brain EEG power and subwaves frequencies in the NTS region after global cerebral ischemia model in male rats. Further findings also demonstrated that EA improves serum antioxidant level which we can conclude that EA increased antioxidant enzymes in the body and subsequently these enzymes might protect neuronal plasticity which finally improve brain electrophysiology pattern.

\section{REFERENCES}

1- Llinas R, Barbut D, Caplan LR. Neurologic complications of cardiac surgery. Prog Cardiovasc Dis. 2000; 43:101-12.

2- Dirnagl U, Iadecola C, Moskowitz MA. Pathobiology of ischaemic stroke: an integrated view. Trends Neurosci. 1999; 22:391-7.

3- Moler FW, Meert K, Donaldson AE, Nadkarni V, Brilli RJ, Dalton HJ, et al. In-hospital versus out-of-hospital pediatric cardiac arrest: a multicenter cohort study. Crit Care Med. 2009; 37:2259-67.

4- Nitatori T, Sato N, Waguri S, Karasawa Y, Araki H, Shibanai K, et al. Delayed neuronal death in the CA1 pyramidal cell layer of the gerbil hippocampus following transient ischemia is apoptosis. J Neurosci. 1995; 15:1001-11.

5- Constantinescu AO, Ilie A, Ciocan D, Zagrean AM, Zagrean L, Moldovan M. Endogenous adenosine A1 receptor activation underlies the transient post-ischemic rhythmic delta EEG activity. Clin Neurophysiol. 2011; 122:1117-26.

6- Husain AM. Electroencephalographic assessment of coma. J Clin Neurophysiol. 2006;23:208-20.

7- Dolatshahi M, Farbood Y, Sarkaki A, Mansouri SM, Khodadadi A. Ellagic acid improves hyperalgesia and cognitive deficiency in 6-hydroxidopamine induced rat model of Parkinson's disease. Iran J Basic Med Sci. 2015; 18:38-46.

8- Assaleh K, Al-Nashash H, Thakor N. Spectral subtraction and cepstral distance for enhancing EEG entropy. Conf Proc IEEE Eng Med Biol Soc. 2005; 3:2751-4.

9- Diedler J, Sykora M, Bast T, Poli S, Veltkamp R, Mellado P, et al. Quantitative EEG correlates of low cerebral perfusion in severe stroke. Neurocrit Care. 2009; 11:210-6.

10- Seltzer LE, Swartz M, Kwon JM, Burchfiel J, Alfieris GM, Guillet R. Intraoperative electroencephalography predicts postoperative seizures in infants with congenital heart disease. Pediatr Neurol. 2014; 50:313-7.

11- Nuwer MR. Intraoperative electroencephalography. J Clin Neurophysiol. 1993; 10:43744. 
Ellagic acid protects brain from I/R

12- Adams DC, Heyer EJ, Emerson RG, Moeller JR, Spotnitz HM, Smith DH, et al. The reliability of quantitative electroencephalography as an indicator of cerebral ischemia. Anesth Analg. 1995; 81:80-3.

13- Kearse LA, Jr., Martin D, McPeck K, Lopez-Bresnahan M. Computer-derived density spectral array in detection of mild analog electroencephalographic ischemic pattern changes during carotid endarterectomy. J Neurosurg. 1993; 78:884-90.

14- Arnold M, Sturzenegger M, Schaffler L, Seiler RW. Continuous intraoperative monitoring of middle cerebral artery blood flow velocities and electroencephalography during carotid endarterectomy. A comparison of the two methods to detect cerebral ischemia. Stroke. 1997; 28:1345-50.

15- Nabavi SF, Dean OM, Turner A, Sureda A, Daglia M, Nabavi SM. Oxidative stress and poststroke depression: possible therapeutic role of polyphenols? Curr Med Chem. 2015; 22:343-51.

16- Wada L, Ou B. Antioxidant activity and phenolic content of Oregon caneberries. J Agric Food Chem. 2002; 50:3495-500.

17- Guven M, Aras AB, Topaloglu N, Ozkan A, Sen HM, Kalkan Y, et al. The protective effect of syringic acid on ischemia injury in rat brain. Turk J Med Sci. 2015; 45:233-40.

18- Farbood Y, Sarkaki A, Dianat M, Khodadadi A, Haddad MK, Mashhadizadeh S. Ellagic acid prevents cognitive and hippocampal long-term potentiation deficits and brain inflammation in rat with traumatic brain injury. Life Sci. 2015; 124:120-7.

19- Pang X, Li T, Feng L, Zhao J, Zhang X, Liu J. Ellagic acid-induced thrombotic focal cerebral ischemic model in rats. J Pharmacol Toxicol Methods. 2014; 69:217-22.

20- Chase MH, Nakamura Y, Clemente CD, Sterman MB. Afferent vagal stimulation: neurographic correlates of induced EEG synchronization and desynchronization. Brain Res. 1967; 5:236-49.

21- Schachter SC, Saper CB. Vagus nerve stimulation. Epilepsia. 1998; 39:677-86.

22- Sapru HN. Carotid chemoreflex. Neural pathways and transmitters. Adv Exp Med Biol. 1996; 410:357-64.

23- Lineberry CG, Siegel J. EEG synchronization, behavioral inhibition, and mesencephalic unit effects produced by stimulation of orbital cortex, basal forebrain and caudate nucleus. Brain Res. 1971; 34:143-61.

24- Maeda M, Nakai M, Krieger AJ, Sapru HN. Chemical stimulation of the nucleus tractus solitarii decreases cerebral blood flow in anesthetized rats. Brain Res. 1990; 520:255-61.

25- Dianat M, Veisi A, Ahangarpour A, Fathi Moghaddam H. The effect of hydro-alcoholic celery (Apiumgraveolens] leaf extract on cardiovascular parameters and lipid profile in animal model of hypertension induced by fructose. Avicenna J Phytomed. 2015; 5:203-9.

26- Yonekura I, Kawahara N, Nakatomi H, Furuya K, Kirino T. A model of global cerebral ischemia in C57 BL/6 mice. J Cereb Blood Flow Metab. 2004; 24:151-8.

27- Girish C, Koner BC, Jayanthi S, Ramachandra Rao K, Rajesh B, Pradhan SC. Hepatoprotective activity of picroliv, curcumin and ellagic acid compared to silymarin on paracetamol induced liver toxicity in mice. Fundam Clin Pharmacol. 2009; 23:735-45.

28- Paxinos G WC. The rat brain in stereotaxic coordinates. Academic Press ed. edition n, editor: Amsterdam; 2007.

29- Cheng CH, Yi PL, Chang HH, Tsai YF, Chang FC. Kappa-opioid receptors in the caudal nucleus tractus solitarius mediate $100 \mathrm{hz}$ electroacupuncture-induced sleep activities in rats. Evid Based Complement Alternat Med. 2012; 2012:715024.

30- Sarkaki A, Eidypour Z, Motamedi F, Keramati K, Farbood Y. Motor disturbances and thalamic electrical power of frequency bands' improve by grape seed extract in animal model of Parkinson's disease. Avicenna J Phytomed. 2012; 2:222-32.

31- Pulsinelli WA, Brierley JB. A new model of bilateral hemispheric ischemia in the unanesthetized rat. Stroke. 1979; 10:267-72.

32- Diler AS, Ziylan YZ, Uzum G, Lefauconnier JM, Seylaz J, Pinard E. Passage of spermidine across the blood-brain barrier in short recirculation periods following global cerebral ischemia: effects of mild hyperthermia. Neurosci Res. 2002; 43:335-42.

33- Leeuwenburgh C, Heinecke JW. Oxidative stress and antioxidants in exercise. Curr Med Chem. 2001; 8:829-38.

34- Roghani M, Baluchnejadmojarad T. Chronic epigallocatechin-gallate improves aortic reactivity of diabetic rats: underlying mechanisms. Vascul Pharmacol. 2009; 51:84-9. 
35- Samarghandian S, Borji A, Delkhosh MB, Samini F. Safranal treatment improves hyperglycemia, hyperlipidemia and oxidative stress in streptozotocin-induced diabetic rats. J Pharm Pharm Sci. 2013; 16:352-62.

36- Turk G, Sonmez M, Ceribasi AO, Yuce A, Atessahin A. Attenuation of cyclosporine Ainduced testicular and spermatozoal damages associated with oxidative stress by ellagic acid. Int Immunopharmacol. 2010; 10:177-82.

37- Plundrich N, Grace MH, Raskin I, Ann Lila M. Bioactive polyphenols from muscadine grape and blackcurrant stably concentrated onto protein-rich matrices for topical applications. Int J Cosmet Sci. 2013; 35:394-401.

38- Spencer WA, Jeyabalan J, Kichambre S, Gupta RC. Oxidatively generated DNA damage after $\mathrm{Cu}$ (II) catalysis of dopamine and related catecholamine neurotransmitters and neurotoxins: Role of reactive oxygen species. Free Radic Biol Med. 2011; 50:139-47.

39- Rojanathammanee L, Puig KL, Combs CK. Pomegranate polyphenols and extract inhibit nuclear factor of activated T-cell activity and microglial activation in vitro and in a transgenic mouse model of Alzheimer disease. J Nutr. 2013; 143:597-605.

40- Hoseiny Nejad KH, Dianat M, Sarkaki A, Naseri MK, Badavi M, Farbood Y. Ellagic acid improves electrocardiogram waves and blood pressure against global cerebral ischemia rat experimental models. Electron Physician. 2015; 7:1153-62.

41- Do KQ, Cabungcal JH, Frank A, Steullet P, Cuenod M. Redox dysregulation, neurodevelopment, and schizophrenia. Curr Opin Neurobiol. 2009; 19:220-30.

42- Mraovitch S, Kumada M, Reis DJ. Role of the nucleus parabrachialis in cardiovascular regulation in cat. Brain Res. 1982; 232:57-75.

43- Al-Nashash HA, Thakor NV. Monitoring of global cerebral ischemia using wavelet entropy rate of change. IEEE Trans Biomed Eng. 2005; 52:2119-22.

44- Bezerianos A, Tong S, Thakor N. Time-dependent entropy estimation of EEG rhythm changes following brain ischemia. Ann Biomed Eng. 2003; 31:221-32.

45- Yu T, Chen QE, Chen ZW, Xiong Z, Ye M. Protective effects of total flavones of rhododendra against global cerebral ischemia reperfusion injury. Am J Chin Med. 2009; 37:877-87.

46- Ilie A, Ciocan D, Constantinescu AO, Zagrean AM, Nita DA, Zagrean L, et al. Endogenous activation of adenosine A1 receptors promotes post-ischemic electrocortical burst suppression. Neuroscience. 2009; 159:1070-8.

47- Kabiraj P, Marin JE, Varela-Ramirez A, Zubia E, Narayan M. Ellagic acid mitigates SNO-PDI induced aggregation of Parkinsonian biomarkers. ACS Chem Neurosci. 2014; 5:1209-20.

48- Uzar E, Alp H, Cevik MU, Firat U, Evliyaoglu O, Tufek A, et al. Ellagic acid attenuates oxidative stress on brain and sciatic nerve and improves histopathology of brain in streptozotocin-induced diabetic rats. Neurol Sci. 2012; 33:567-74.

49- Hassoun EA, Vodhanel J, Holden B, Abushaban A. The effects of ellagic acid and vitamin $\mathrm{E}$ succinate on antioxidant enzymes activities and glutathione levels in different brain regions of rats after subchronic exposure to TCDD. J Toxicol Environ Health A. 2006; 69:381-93.

50- Hassoun EA, Vodhanel J, Abushaban A. The modulatory effects of ellagic acid and vitamin E succinate on TCDD-induced oxidative stress in different brain regions of rats after subchronic exposure. J Biochem Mol Toxicol. 2004; 18:196-203.

51- Ghosh N, Ghosh R, Mandal SC. Antioxidant protection: A promising therapeutic intervention in neurodegenerative disease. Free Radic Res. 2011; 45:888-905.

52- Valko M, Leibfritz D, Moncol J, Cronin MT, Mazur M, Telser J. Free radicals and antioxidants in normal physiological functions and human disease. Int $\mathrm{J}$ Biochem Cell Biol. 2007; 39:44-84.

53- Xie YG, Mu HJ, Li Z, Ma JH, Wang YL. Supression of chronic central pain by superoxide dismutase in rats with spinal cord injury: Inhibition of the NMDA receptor implicated. Exp Ther Med. 2014; 8:1137-41.

54- Carmeli C, Knyazeva MG, Cuenod M, Do KQ. Glutathione precursor N-acetyl-cysteine modulates EEG synchronization in schizophrenia patients: a double-blind, randomized, placebocontrolled trial. PLoS One. 2012; 7:e29341. 
Ellagic acid protects brain from I/R

55- Tyurenkov IN, Perfilova VN, Popova TA, Ivanova LB, Prokofiev, II, Gulyaeva OV, et al. Changes in oxidant and antioxidant status of females with experimental gestosis under the effect of GABA derivatives. Bull Exp Biol Med. 2013; 155:363-5.

Received: February 03, 2016; Accepted: July 14, 2016 